\title{
Control of oral anticoagulant treatment by chromogenic prothrombin assay
}

\author{
J R O'DONNELL, * ISOBEL D WALKER, $†$ J F DAVIDSON $\dagger$ \\ From the Departments of Haematology, *Victoria Infirmary, and the $\nmid$ Royal Infirmary, Glasgow, Scotland
}

SUMMARY Doses of oral anticoagulants in 50 patients on long term treatment were easily and satisfactorily monitored over six months by an automated chromogenic assay of prothrombin (CPA). It is suggested that chromogenic assay of one or more of the vitamin $\mathrm{K}$ dependent coagulation factors would provide a readily standardised alternative to those conventional tests which depend on human brain derived reagents, now regarded as a biohazard.

Until the widespread introduction of British Comparative Thromboplastin in $1970^{1}$ paved the way to standardisation, serious difficulties due to variable sensitivities of thromboplastins had impeded the safe and effective control of oral anticoagulant treatment. Further improvements followed the introduction of the National External Quality Assessment Scheme (NEQAS) in coagulation. ${ }^{2}$ The recent availability of primary and secondary World Health Organisation (WHO) reference thromboplastins from human and animal brain ${ }^{3}$ permitted international conformity in reporting results by an International Normalised Ratio (INR) closely corresponding to the British Corrected Ratio (BCR) (later British Ratio (BR)) and an International Sensitivity Index (ISI) for calibration of thromboplastins. ${ }^{4-6}$ This work has enabled more realistic yet safe recommendations to be made for therapeutic ranges in anticoagulant treatment. ${ }^{78}$

Concern has arisen, however, about the use of reagents derived from human brain, with recent reports of deaths from Creutzfeldt-Jakob disease (CJD) after the administration of pituitary extracted human growth hormone. ${ }^{9}$ The causative agent of CJD is highly resistant to chemical and physical decontamination, including preservation of brain in phenol and formalin. ${ }^{10}$

Further anxiety has followed the suggestion that unconventional slow virus infections may be implicated in acquired immune deficiency syndrome (AIDS) encephalopathy, ${ }^{11}$ which bears a striking similarity to other spongiform encephalopathies such as CJD, Kuru, and Scrapie. ${ }^{12}$ In addition, some laboratory reagents derived from human plasma have

Accepted for publication 13 November 1986 been found to contain the antibody to human immunodeficiency virus (HIV). ${ }^{13}$ Because of the evidence that the AIDS virus may be present in central nervous system tissue, the major step of discontinuing manufacture of the widely used Manchester Comparative Reagent (MCR) has been taken because of potential biohazard to processing staff (Poller L, personal communication from the United Kingdom Reference Laboratory for anticoagulant reagents and control, January 1986).

It has been estimated that 2.3 million tests are performed annually in the United Kingdom to control oral anticoagulant treatment, ${ }^{7}$ with over $90 \%$ of laboratories using human thromboplastin. It is therefore a matter of urgency to assess critically methods of controlling anticoagulant treatment that are as independent as possible of biological reagents. Amidolytic assays using chromogenic peptide substrate analysis are known to provide such methodology and have been advocated by many workers ${ }^{14-20}$ without achieving widespread use. Presumably because of the satisfactory control available with well established global clotting tests such as prothrombin time using $\mathrm{BCT}$, there has been some reluctance to adopt these novel methods which do not depend on the formation of a fibrin clot as an end point. $\mathrm{We}^{21-23}$ have shown preliminary evidence of a good correlation between chromogenic peptide substrate assay and the prothrombin time and Thrombotest. The present study was undertaken to establish whether an automated chromogenic peptide substrate assay could be used as sole monitor of dose in a group of patients on long term treatment with Warfarin and a smaller group of patients in initial phase treatment; the performance of the chromogenic peptide substrate assay was compared with that of both INR (BCR) and Thrombotest. 


\section{Material and methods}

Plasma samples from 50 patients, aged 20-69 years, attending a large anticoagulant clinic were studied over six months. The only basis for selection was that all had been on long term anticoagulation (warfarin BP) following insertion of cardiac valve prostheses, and had been treated for periods ranging from one to several years. Samples were obtained at monthly intervals in almost all cases. Dosage was regulated by one of the group on the same day on the basis of chromogenic peptide substrate assay results, without knowledge of the INR (BCR) and Thrombotest. Immediately after insertion of cardiac prosthetic valves seven inpatients were additionally monitored daily for 10 days after treatment with Warfarin had been started.

\section{LABORATORY METHODS}

Plasma samples for prothrombin time estimation were tested in duplicate and prepared from venous blood that had been collected into a one tenth volume of $3.8 \%$ sodium citrate. The thromboplastin used was the $\mathrm{MCR}^{2}$ and results were expressed as INR (BCR). Normal control plasmas were prepared from a pool of seven healthy volunteer adults and used for day to day precision of the chromogenic peptide substrate assay independent of the lyophilised reference plasma used for construction of standard lines. Thrombotest was done immediately on venous whole blood according to the manufacturer's instructions (Nyegaard and Co, Oslo, Norway). For the chromogenic peptide substrate assay, three independently calibrated lyophilised human plasma samples (prothrombin standard, "Precichrom" I (normal) and "Precichrom" II (artificially depleted of vitamin K dependent clotting factors)) were obtained from Boehringer UK, and test kits for the chromogenic peptide substrate assay were also obtained from these manufacturers.

The chromogenic substrate used was chromozym TH (TOS-GLY-PRO-ARG-pNA) with activation of prothrombin in the presence of calcium, factors $\mathrm{V}$, $\mathrm{Xa}$, and cephalin (rabbit). An automated assay was used based on the method of Svendsen et $a l^{26}$ and modified as fully described previously by the present group. ${ }^{23}$ Plasma $(5 \mu \mathrm{l})$ was immediately diluted with $0.1 \mathrm{ml}$ of $0.15 \mathrm{M}$ sodium chloride, then $1 \mathrm{ml}$ of the activator reagent, reconstituted in the proportion $10 \mathrm{ml}$ buffer: $1 \mathrm{ml}$ cephalin: $0 \cdot 1 \mathrm{ml}$ factors $\mathrm{V}$ and $\mathrm{Xa}$ was added to the reaction mixture, and after five minutes of incubation at $25^{\circ} \mathrm{C} 0 \cdot 1 \mathrm{ml}$ chromozym TH was added. The progress of the reaction, as rate of change of absorbance $(\Delta \mathrm{A} /$ minute) was monitored for 20 seconds at $405 \mathrm{~nm}$. The automated analyser used was the Gilford System 203-S, obtained from
Corning Medical and Scientific Ltd, UK.

The prothrombin concentration $(\%)$ for test plasma samples was derived by comparing their $\Delta \mathrm{A} /$ minute values with those of a series of reference plasma dilutions, after having constructed a standard line.

\section{Results}

\section{ASSAY PERFORMANCE}

The standard line constructed from the $\Delta \mathrm{A} /$ minute values for saline dilutions of the reference plasma was found to be linear up to $175 \%$ of the normal prothrombin concentration. Table 1 shows the day to day precision (interassay variation) as coefficient of variation $(\mathrm{CV})$ for the three tests studied. A measure of the accuracy of the automated chromogenic peptide substrate assay was obtained by comparing the assay results with the manufacturers' assigned values for a prothrombin standard and calibrated control plasmas (table 2). The minimum detectable prothrombin value was estimated at $2.5 \%$.Carry over of samples was negligible $(1 \cdot 2-1 \cdot 8 \%)$. Full details of an evaluation of performance and quality assurance of the automated chromogenic peptide substrate assay at an early stage in this study have already been reported. $^{23}$

\section{COMPARISON OF METHODS}

Two hundred and sixty two plasma samples were analysed from the patients receiving longterm Warfarin. The results of the automated chromogenic peptide substrate assay were compared with (a) INR (BCR) and (b) Thrombotest. A standard "least squares" linear regression ( $\mathrm{Y}$ on $\mathrm{X}$ ) would not be appropriate for comparing two laboratory methods

Table 1 Interassay coefficients of variation for plasmas of "high" and "low" prothrombin values

\begin{tabular}{lll}
\hline Test & High & Low \\
\hline Chromogenic prothrombin assay (CPA) & 3.53 & $6 \cdot 14$ \\
Thrombotest (TT) & $7 \cdot 82$ & $7 \cdot 14$ \\
British corrected ratio (BCR) & 4.03 & $5 \cdot 85$ \\
\hline
\end{tabular}

Table 2 Accuracy of automated prothrombin amidolytic assay

\begin{tabular}{lll}
\hline Sample & $\begin{array}{l}\text { Assigned } \\
\text { value\% }\end{array}$ & $\begin{array}{l}\text { Determined } \\
\text { value \% }\end{array}$ \\
\hline (Lyophilised plasmas) & & \\
Prothrombin standard & 83 & 80 \\
"Precichrom" I & 78 & 79 \\
"Precichrom" II & 42 & 44 \\
\hline
\end{tabular}


where errors of measurement may be associated with both $\mathrm{X}$ and $\mathrm{Y}$. Deming's functional analysis was applied as it has been found to be the most useful way of estimating the known slope of a regression line when the independent variable is measured with imprecision. ${ }^{24}$ The Deming method provides the same correlation coefficient $(r)$ as standard linear regression but does affect the regression line, avoiding error due to outlying points. This may be of clinical importance as in this study a therapeutic range of $12 \cdot 6 \%-38 \cdot 4 \%$ for prothrombin was derived from the equation of the Deming regression line of chromogenic peptide substrate assay on INR (BCR) compared with a wider range of $9 \cdot 1 \%-41 \cdot 5 \%$ using standard linear regression. The therapeutic range used for INR (BCR) was $2 \cdot 0-4.0 ; 5-11 \%$ for Thrombotest (table 3). The " $r$ " values are shown for the whole range of measurements and separately for those within the therapeutic ranges, providing maximum information on agreement of results. All the " $r$ " values were highly significant ( $p<0.001)$. The good correlation between tests is well shown by concordance "boxes", a diagrammatic alternative to " $r$ " values (figure). The correlation graph is sectioned into ranges of therapeutic equivalence. The proportion of data points which lie within the areas of common therapeutic equivalence, when summed, were described as "fully concordant" results. Those points which seemed to be overdosed with Warfarin by one method and underdosed by another are described as "discordant" results. Remaining points were described as being "partially concordant". There was "fully concordant" information in $87 \%$ of patients and "discordant" information in none.

No problems were encountered regulating the doses of Warfarin on the basis of chromogenic peptide substrate assay results alone. There were no haemorrhagic or thrombotic episodes, and at no time did it become necessary for the other members of the group, also aware of the results of INR (BCR) and Thrombotest, to divulge them. Automated chromogenic peptide substrate assay results were available rapidly (60 samples in 40 minutes).

Table 3 Correlation coefficients with significance values for $(C P A) v(B C R)$ and Thrombotest within and without therapeutic ranges

\begin{tabular}{lll}
\hline & $\begin{array}{l}\text { Correlation } \\
\text { coefficient }(r)\end{array} \quad p$ value \\
\hline $\begin{array}{l}C A \text { A } B C R \\
\text { (All data) } \mathrm{n}=262\end{array}$ & & \\
(In therapeutic range) $\mathrm{n}=216$ & 0.815 & $<0.001$ \\
$C P A v$ Thrombotest & 0.687 & $<0.001$ \\
(All data) $\mathrm{n}=262$ & & $<0.001$ \\
(In therapeutic range) $\mathrm{n}=196$ & 0.822 & $<0.001$ \\
\hline
\end{tabular}

Chromogenic prothrombin (\%)

\begin{tabular}{lc|c|c|c|}
\cline { 2 - 4 } $\begin{array}{l}\text { Chromogenic } \\
\text { prothrombin (\%) }\end{array}$ & 38 & 7.3 & 3.4 & 0 \\
\cline { 2 - 4 } & 13 & $4 \cdot 2$ & $76 \cdot 3$ & $2 \cdot 3$ \\
\cline { 2 - 4 } & 0 & $2 \cdot 7$ & 3.8 \\
\hline \multicolumn{4}{|c|}{ 2 BCR 4 }
\end{tabular}

Figure Concordant classification of patients based on therapeutic ranges for BCR and chromogenic prothrombin results

The second part of the study, on a small group of 용 patients in initial phase treatment studied over 10 \& days, showed that a median period of four days or (range 3.6-5.5) elapsed before the therapeutic range in for chromogenic peptide substrate assay was reached. During this period control was monitored on the 의 basis of INR (BCR).

\section{Discussion}

Application of chromogenic substrate analysis to $\stackrel{Ð}{v}$ many aspects of haemostasis and thrombosis continues to grow but so far not in the large routine area of oral anticoagulant control. Although patients stabilised on long term oral anticoagulant treatment show a similar reduction in each of the vitamin $K$ dependent factors, there has been reluctance to accept that well established global methods which measure the prothrombin complex (factors X, VII, and II) might safely be replaced by an amidolytic chromogenic assay of only one member of the complex. The present study has shown a good correlation between automated chromogenic peptide substrate assay and the two most widely used global clotting tests, prothrombin time and Thrombotest. In addition, a very good correlation has been found between a one stage clotting assay of prothrombin and the chromogenic method $(r=0.90){ }^{21}$

Apart from the enormous advantage of chromo- $\frac{T}{O}$ genic substrate analysis not depending on reagents derived from human brain, there are other major $\stackrel{\sim}{\sigma}$ benefits over biological tests such as prothrombin $N$ time, in essence a version of Quick's 50 year old test. ${ }^{27}$ N Conventional clotting tests permit limited access to automation, to which amidolytic assays are highly susceptible; photometric assays permit more satisfactory standardisation, ${ }^{28}$ and large batches of samples may quickly be assayed with the standard equipment of clinical chemistry, ${ }^{29}$ or with smaller numbers by the manual chromogenic method. ${ }^{21}$ The present study shows that the automated method was easy to apply, accurate, and sensitive, with negligible sample carry over. Very small volumes of plasma were used, 
allowing dilution and thereby minimising the influence of inhibitors ${ }^{20}$ and exposure to laboratory reagents. The method may readily be adapted to allow finger prick sampling.

It has been recommended that selected patients, such as those with cardiac prosthetic valves, would benefit from intensified oral anticoagulation yet could be safely controlled at an INR (BCR) of $3 \cdot 0-4 \cdot 5 .^{78}$ No special effort was made to intensify control in this study using chromogenic peptide substrate assay results, but this would not have posed problems as the therapeutic range is wide and the lower limit of detection of the assay was $2.5 \%$ prothrombin.

A limitation of chromogenic assay of one of the vitamin $\mathrm{K}$ dependent factors arises with patients in the initial phase of anticoagulation, as shown in this study. This is because of the wide variation in half life of factors $\left(\mathrm{T}^{1} 1 / 2\right)$, from factor VII at four to six hours to factor II (prothrombin) at 48-96 hours. ${ }^{29}$ The resultant therapeutic "hiatus" suggests that neither factor $X\left(T^{1} 1 / 240-60\right.$ hours) nor prothrombin are ideal for initial phase treatment, but it has been suggested that a chromogenic assay of factor $1 \mathrm{X}(\mathrm{T} 1 / 2 \quad 18-30$ hours) might be suitable, ${ }^{31}$ while the large biological variation of factor VII, despite a short T $1 \frac{2}{2}$, makes it less appropriate. ${ }^{30}$ The use of a broad spectrum photometric prothrombin time test measuring all members of the prothrombin complex should also permit effective control of initial phase Warfarin treatment.

This study makes no claim other than that an automated chromogenic peptide substrate assay provided safe rapid control in a large group of patients on long term treatment with Warfarin. A good correlation was obtained when the chromogenic results were compared with those obtained from conventional broad spectrum clotting tests. Arguments as to whether these new amidolytic assays provide "Bioequivalence" to traditional methods seem to derive from a reluctance to give up the end point of a fibrin clot rather than on reality.

The withdrawal of MCR because of potential biohazard as a reagent derived from human brain is unfortunate because of its widespread use and tested performance. It is now suggested that automated chromogenic substrate analysis can provide an alternative method, which, potentially, is as susceptible to international standardisation as MCR and dependent to the minimum possible extent on biological reagents. Urgent large scale evaluation of these methods is now required.

We thank Dr J Conkie and Mrs F McCall of the Thrombosis Research Group at Glasgow Royal Infirmary for invaluable technical help and $\operatorname{Dr} \mathrm{A}$ McClelland, department of biochemistry, Glasgow Royal Infirmary, for major statistical advice.

\section{References}

1 Alderson MR, Poller L, Thomson JM. Validity of British system for anticoagulant control using national reagents. J Clin Pathol 1970;23:281-5.

2 Poller L. The British system of anticoagulant control. Thromb Haemost 1975;33:157-62.

3 World Health Organisation. Expert Committee on Biological Standardisation. Requirements of thromboplastins and plasma used to control oral anticoagulant therapy. Geneva: World Health Organisation, 1983:81-105.

4 Loeliger EA, Lewis SM. Progress in laboratory control of oral anticoagulants. Lancet 1982;ii:318-20.

5 Shinton NK. Standardisation of oral anticoagulant treatment. $\mathrm{Br}$ Med J 1983;287:1000-1.

6 Loeliger EA, Poller L, Samama M, et al. Questions and answers on prothrombin time standardisation in oral anticoagulant control. Thromb Haemost 1985;54:515-7.

7 British Committee for Standardisation in Haematology (BSCH) Guidelines on oral anticoagulation. London: British Society for Haematology, 1984:1-20.

8 Poller L. Therapeutic ranges in anticoagulant administration. Br Med J 1985;290:1683-6.

9 Powell Jackson J, Weller RO, Kennedy P, et al. CrestzfeldtJakob disease after administration of human growth hormone. Lancet 1985;ii:244-6.

10 Tateishi J, Kitamoto T, Hiratani H. Creutzfeldt-Jakob disease pathogen in growth hormone preparations is eliminatable. Lancet 1985;ii:1299-300.

11 Goldwater PN, Synek BJL, Koelmeyer TD, Scott PJ. Structures resembling scrapie associated fibrils in AIDS. Lancet 1985;ii:447-8.

12 Goldwater PN, Synek BJL, Koelmeyer TD, Scott PJ. Scrapieassociated fibrils and AIDS encephalopathy. Lancet 1985;ii: 1300 .

13 Jones P, Hamilton PJ, Oxley A, et al. Anti-HTLV-III positive laboratory reagents. Lancet 1985;i:1458-9.

14 Bergstrom K, Blomback M. Determination of plasma prothrombin with a reaction rate analyser using synthetic substrate. Thromb Res 1974;4:719-29.

15 Axelson G, Korsan-Bengsten K, Waldenstrom J. Prothrombin determination by means of a chromogenic peptide substrate. Thromb Haemost 1976;36:517-24.

16 Bergstrom K, Egberg N. Determination of vitamin K sensitive coagulation factors in plasma. Studies on three methods using synthetic chromogenic substrates. Thromb Res 1978;12: 531-47.

17 Lammle B, Eichlisberger R, Hanni L, et al. Controlle der Oralen Antikoagulation: Vergleich Zwischen Quick und Kolorimetrischer Factors X-Bertimmung bei Patieiten. Schweiz Wochenschr 1979;109:115-9.

18 Bertina RM, Loeliger EA. The potential use of chromogenic substrates in the routine monitoring of oral anticoagulant therapy. In: Lijnen HR, Collen D, Verstraete M, eds. Synthetic substrates in clinical blood coagulation assays. The Hague: Martinus Nijhoff, 1980:13-25.

19 Erskine JG, Walker ID, Davidson JF. Maintenance control of oral anticoagulant therapy by a chromogenic substrate assay for factor X. J Clin Pathol 1980;33:445-8.

20 Scully MF, Kakkar VV. Chromogenic peptide substrates in the measurement of coagulation factors. In: Roath S, ed. Topical review's in haematology. Vol 2. Bristol: PG Wright, 1982:185-207.

21 O'Donnell JR, Walker ID, Davidson JF. Control of oral anticoagulant therapy with a chromogenic prothrombin assay. Br J Haematol 1983;55:172.

22 O'Donnell JR, Walker ID, Singer CRJ, Davidson JF. Control of dosage of oral anticoagulant therapy using an automated chromogenic prothrombin assay. $\mathrm{Br} J$ Haematol 1984;58:171-2.

23 Conkie JA, McCall F, Walker ID, Davidson JF. Evaluation of an 
automated prothrombin assay using a chromogenic substrate. Haemostas 1984:14:307-11.

24 Cornbleet PJ, Gochman N, Incorrect least-squares regression coefficients in method comparison analysis. Clin Chem 1979:432-8.

25 Thomson JM. Laboratory control of anticoagulant therapy. In: Thomson JM, ed. Blood coagulation and haemostasis-a practical guide. 2nd ed. Edinburgh: Churchill Livingstone. 1980:282-5

26 Svendsen LG, Fareed J, Walenga JM, et al. Newer synthetic peptide substrates in coagulation testing some practical considerations for automated methods. Sem Thromb Haemost 1983;9:250-62

27 Quick AJ. Prothrombin in haemophilia and in obstructive jaundice. J Biol Chem 1935;109:23-4.

28 Stormorken J. A new era in the laboratory evaluation of coagu- lation and fibrinolysis. Thromb Haemost 1976;36:299-301.

29 Kirchhof BRJ, Muller AD, Vermeer C. et al. Control of anticoagulant therapy with a chromogenic substrate. Haemostas 1979:8:1-7.

30 Hjort PF. Egeberg O. Mikkelsen S. Turnover of prothrombin. factor VII and factor IX in a patient with haemophilia A Scand J Clin Lah Invest 1961;13:668-74.

31 Van Dieijen-Visser MP. Van Wersch J, Brombacher PJ, et al. Use of chromogenic peptide substrates in the determination of plasma of patients treated with oral anticoagulants. Haemostas 1982:12:241-55.

Requests for reprints to: Dr JR O'Donnell, Department of Haematology, Victoria Infirmary, Glasgow G42 9TY, Scotland. 